\title{
Biodiversity of flora and fauna of the territory allocated for carrying out construction work for the reconstruction of Highway 217 of the Socialist Republic of Vietnam
}

\author{
Elena Latushkina ${ }^{1, *}$, and Tao Thi Chung Thuy ${ }^{1}$ \\ ${ }^{1}$ Peoples' Friendship University of Russia (RUDN University), 115093, Podolskoe shosse, 8-5, \\ Moscow, Russia
}

\begin{abstract}
The sresearch is devoted to the study of the biological diversity of the anthropogenically transformed territory, the 217 Highway of the Socialist Republic of Vietnam. This highway crosses the northern part of the country from west to east. It is of great strategic importance, since it is the link of many settlements of the country. Along with this, the western section of the road, from 107 to $195 \mathrm{~km}$, requires construction work. Reconstruction of the highway will lead to a whole complex of environmental impacts on the natural environment. The assessment of the impact of anthropogenic object, namely the 217 Highway on the environment during the reconstruction and operational phase requires updating of existing data on the biological diversity of the territory located 40-50 meters from each side of the western section of the 217 Highway. The data obtained from the results of our own observations, the analysis of the available materials of descriptive ecology, surveys of local people, hunters, and forestry workers made it possible to clarify the available information on the species diversity of terrestrial and aquatic ecosystems. Species diversity of agricultural ecosystems is characterized by poverty caused by human economic activity. Together with this, the withdrawal of agricultural land for the construction of a highway will result in the death of 31342 individuals of fruit and forest trees in the province of $\mathrm{Ba}$ Thyok and 68424 individuals of trees and shrubs in the province of Kuang Shon. The biological diversity of natural ecosystems is much richer. However, the influence of the highway can contribute to the inhibition of plants, contribute to the dissection of the habitat of animals and their death.
\end{abstract}

\section{Introduction}

The Highway 217 is located in the province of Thanh Hoa and crosses the Socialist Republic of Vietnam from west to east, from the settlement on the border with Laos $\mathrm{Na}$ Meo to the highway number one in the Ha Chung district.

\footnotetext{
*Corresponding author: elena_latushkina@mail.ru
} 
The motorway connects five districts and connects small towns of local importance. The motorway passes through such major automobile roads as the National Highway 45, Ho Chi Minh Highway, as well as the National Road 15A and reaches the western border of the country with Laos.

5 large rivers and 264 small rivers and streams flow in the province of Thanh Hoa. The Highway 217 passes through the Ma River and touches the Lo and Luong rivers, which are tributaries of Ma, as well as small rivers and streams. Most of the settlements are located near the connecting highway and the abovementioned water reservoirs. The quality of the population largely depends on the quality of the water reservoirs [1].

At present the Highway 217's section from 107th to 195th kilometer, from the intersection of Highway 15 to the border crossing of Nao Meo in the Thanh Hoa province, does not meet modern requirements and needs reconstruction. In this regard, the Government of Viet Nam has decided to develop the project and conduct construction work to reconstruct one of the state highways, namely the 217 Highway.

To conduct an environmental impact assessment of construction works and to monitor the environment during highway operation, it is necessary to make a detailed description containing a list of plant and animal species prior to the start of construction work.

\section{Problem Statement}

The construction of roads for the restoration, laying, strengthening, expansion of the roadway, the creation of road infrastructure is associated with the seizure of land, cutting of shrub and woody plants, violation of habitats of living creatures and other environmental impacts on the environment. For a project assessment of these impacts, it is necessary to compile a list of species of plants and animals whose distribution area coincides with the territories involved in the construction.

\section{Research Questions}

The study is aimed at obtaining answers to the following questions: What is the list of species of plant and animal communities living at a distance of 40-50 m on both sides of the central longitudinal axis of the anthropogenic object, the 217 Highway? What kinds of flora and fauna will suffer as a result of construction works for the reconstruction of the 217 Highway on the section of 107-195th km? How many plants will die?

\section{Purpose of the Study}

The purpose of the study is to characterize the biological diversity of the flora and fauna of the territory allocated for the construction of the 217 Highway (107-195th km) of the Socialist Republic of Vietnam.

\section{Research Methods}

The study was carried out between 2015 and 2017 a section of the 217 Highway of a total length of $88 \mathrm{~m}$. The width of the surveyed area was $80-100 \mathrm{~m}, 40-50 \mathrm{~m}$ on both sides of the central point of the cross-section of the roadway. The research methods were:

5.1. Observation. This method was used in the field, it was supposed to fill in the protocols, in which the species of plants and animals found along the highway were fixed. 
5.2. The polls were used to obtain information on the species composition of the territory according to the data of local residents, hunters, forestry, and rural workers.

5.3. Qualitative and quantitative analysis. With the help of this method, a list of species and the number of plants to be cut due to construction.

\section{Findings}

According to the results of research, representatives of 2608 species and 211 families of vascular plants live in the province of Thanh Hoa. The vegetation of agricultural areas is characterized by the presence of annual plants (rice, corn, potatoes, sweet potatoes, beans, vegetables, etc.) and perennials (tea, fruit trees, etc.).

In the studied area, biological diversity is represented by 124 species of animals belonging to the 31 st family, of which bats (Chiroptera) represent the most numerous family in number of species $-38(30,6 \%)$. Carnivora -31 species $(25 \%)$, Rodentia - 22 species $(17,7 \%)$, Primates -12 species $(9,6 \%)$, Artiodactyla -11 species $(8,8 \%)$. The following species inhabit the territory: Lagomorpha, Insectivora, Scandenta, Pholidota, Dermoptera, and Proboscidae among Perissodactyla. We should also mention Vespertilionidae, Hipposideridae, Viveridae, Muridae, which have ten or more species. Nine species were noted in the family of Cercopithecidae, eight -Mustelidae and Felidae, six -Sciuridae. The rest of the families include no more than five species.

The biological diversity of birds is characterized by 293 species from 38 families in 11 suborders, of which sparrows account for the largest number of species and families: 38 families, 192 species (65.5\%). The family of kingfishers is represented by 17 species, falcons - 16 species, woodpeckers -15 species, pigeons -14 species, cuckoo -12 species, etc.

Birds are distributed in three geomorphologically homogeneous areas. The largest number of species lives in hilly and mountainous areas. Less of them are in urbanized areas, fields, and residential areas.

Biological diversity includes 73 species of reptiles. Thus, frogs belong to 18 families, three suborders, two classes; 50 species of reptiles belong to 15 families, two suborders. 23 species of amphibians belong to three families, one suborder. Among them, the family of Ranidae (real frogs) is dominated by 18 species, then the Colubridae goes with 16 species, the family of Emydidae (tortoises) amounts to 7 species, the rest of them have 1-5 species.

Wetland ecosystems. Aquatic plants (Macrophyte) have 34 species of aquatic plants belonging to vascular spore (Pteridophyta) and industrial (Spermatophyta) seed plants, which are distributed in the territories of river waters, streams, ponds, and submerged fields. Aquatic plants can participate in the natural treatment of polluted waters. Some species are used in wastewater treatment of food industry enterprises, hospitals, for example, the reed Phragmitis comunis Trin, some species of algae, duckweeds. There are 93 species of phytoplankton were found in various water bodies. This diatom algae (Bacillariophyta) - 32 species (35\%), algae (Cyanophyta) - 17 species (18\%), green algae (Chlorophyta) - 29 species (31\%), and Euglenophyta -12 species (13\%), etc.

There are 53 species of zooplankton belonging to copepod crustaceans, branching crayfish, rotifers, shellfish, and insect larvae in water bodies. In the composition of zooplankton, the branching crawfish occupy the highest percentage of species composition $(41 \%)$, There are also the following species: rotifers (28\%), copepods (23\%), copepods (4\%), and larval insect groups (4\%).

More than that, there are 29 species of benthos. The group of mollusks: MolluscaGastropoda -11 species. The group of bivalve mollusks: Mollusca-Bivalvia -9 species. The group of shrimp crustaceans: Crustacea-Macrura -7 species, etc. 
We identified 105 species from 98 genera, 45 families, eight suborders of aquatic insects, including Ephemeroptera, Plecoptera, Tricoptera, Megaloptera, and Diptera.

In the composition of fish in ponds and lakes, carp, tilapia, representatives of salmonids, and many others are most common.

The seized land for construction work from forestry, agriculture, and housing will require the cutting of 31342 trees and shrubs in the province of Ba Thuok and the cutting of 68424 individuals of trees and shrubs in the province of Kuang Shon. In the Bah Taqyok province, there will be cut 2688 fruit trees and 12648 forest species. 15060 fruit trees and 52268 forest species will be cut in the province of Kuang Shon

It is predicted that construction work may lead to the death of a number of representatives of the animal world due to the intrusion into their habitat and the exposure of animals to humans.

\section{Conclusion}

The obtained data allow us to update and expand the available materials of descriptive ecology. This description can serve as a reference point for further monitoring studies on the ecological description of the investigated territory.

\section{References}

1. G. V. Pozdnyak, The atlas of the world (Kartographiya, Oniks, Moscow, 2010)

2. Y. V. Ragulina, A. V. Bogoviz, A. N. Alekseev, Advances in Intelligent Systems and Computing, 622, 568-573 (2018) 